\title{
DETECTION OF COTININE IN PASSIVE SMOKERS EXPOSED TO ENVIRONMENTAL TOBACCO SMOKE
}

\author{
Shadiya Fawzul Ameer, Mathi Kandiah
}

\begin{abstract}
Environmental tobacco smoke (ETS) is the main cause of second hand smoking (SHS) induced disease conditions such as chronic obstructive pulmonary disease (COPD), lung cancer, vascular cancer and other types of cancers. It was estimated by the Health and Social Care Information Center (HSCIC) in UK that in the year 2016, 16 million people worldwide between the ages of 16 - 35 years died of smoking related diseases. Hence, different analytical techniques based on mass spectrometry (MS) and chromatography were developed, to detect the presence of tobacco metabolites in body fluids. These tobacco biomarkers in different body fluids could be used to correlate the level of ETS exposure. Among all the tobacco metabolites, cotinine was studied to be the most reliable biomarker, since it does not get affected by other environmental factors and it has along half-life $\mathrm{f} 17$ hours. Therefore, by studying the levels of SHS, smoking cessation programs in public places like schools, parks and public transports could be reinforced in order to protect the innocent lives who are being exposed to tobacco smoke. This review mainly focuses on the detection of cotinine in saliva, serum, urine and hair. In conclusion, it was evident that cotinine detection in hair was the most reliable biological matrix to detect ETS exposure in passive smokers.
\end{abstract}

Keywords: Detection, Cotinine, Analytical Techniques, Body Fluids, Passive Smoking

\section{Introduction}

Environmental tobacco smoke is a global threat. Since the early 1970s environmental tobacco smoke (ETS) is considered to be a major health problem in young and the elderly, mainly due to varied concentration and exposure profiles to the carcinogens present in tobacco smoke (Ramdzan et al., 2016; Woodward et al., 2005; Al-Demaiy, Crane \& Woodward, 2002). This results in approximately 1.1 billion individuals being exposed to tobacco smoke, which makes every sixth human being a second hand smoker (SHS). In addition, the carcinogens present in tobacco are estimated to cause $\sim 5$ million deaths per annum around the globe (Royal college physicians, 2016). Figure 1 illustrates the prevalence of tobacco smoke and the disease condition caused by it around the globe.

Therefore, research scientists are developing different analytical techniques based on mass spectrometry (MS) and chromatography to detect the presence of tobacco biomarkers in body fluids. This could be used to determine exposure of tobacco smoke and to validate abstinence in smoking cessation programs (O'Malley et al., 2014). 


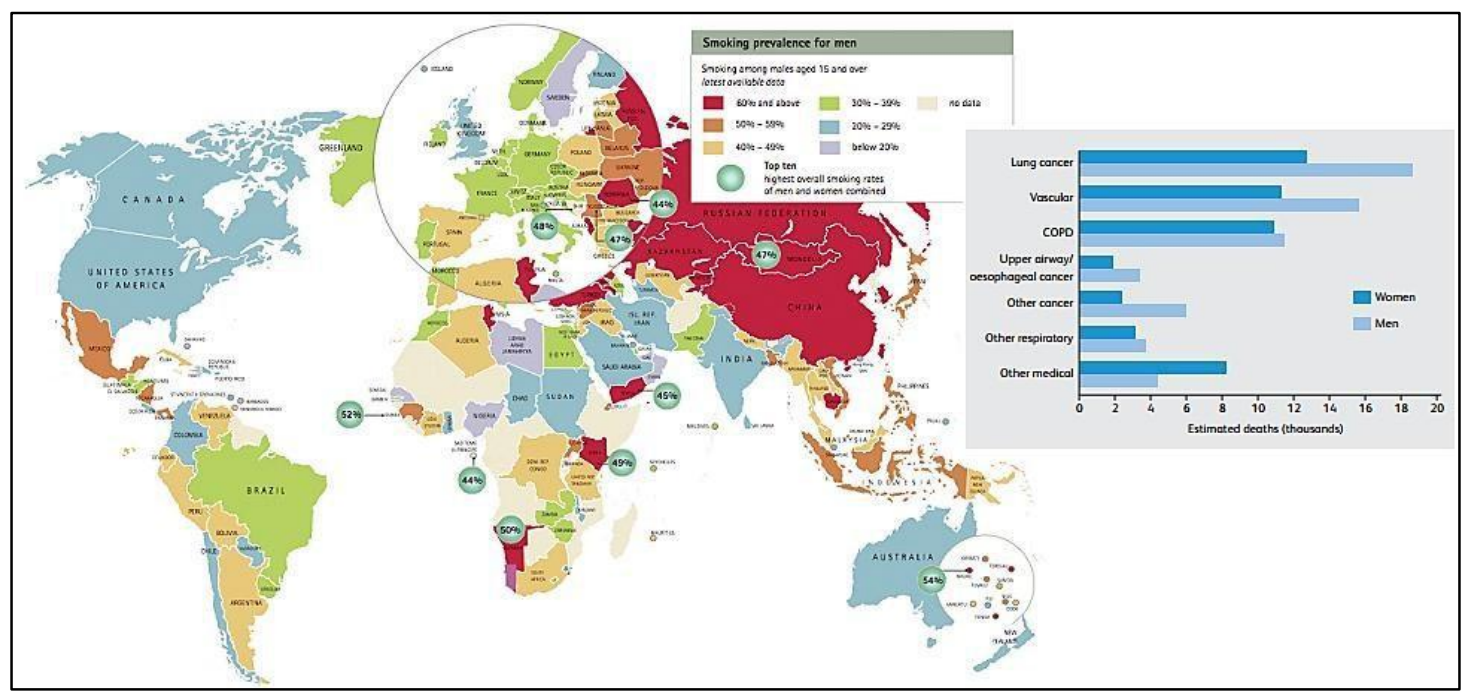

Figure1: Describes the prevalence of ETS around the globe. Different countries are exposed to varied concentration of tobacco. The red regions are those that are highly prevalent to tobacco and green regions are least prevalent. Disease conditions such as; chronic obstructive pulmonary disease (COPD), lung cancer, vascular cancer and other types of cancer are caused due to SHS (Royal College Physicians, 2016).

According to the 2016, statistical compendium report presented by the Health and Social Care Information Center (HSCIC), in the UK. It stated that there were 16 million hospital admissions for adults aged 35 and above due to SHS related diseases. This is approximately 4500 admissions per day. In 2013, 16 percent of all deaths of adults aged 35 and above was due to passive smoking related problems. Figure 2 illustrates the disease conditions presented due to passive smoking (Niblet, 2015).

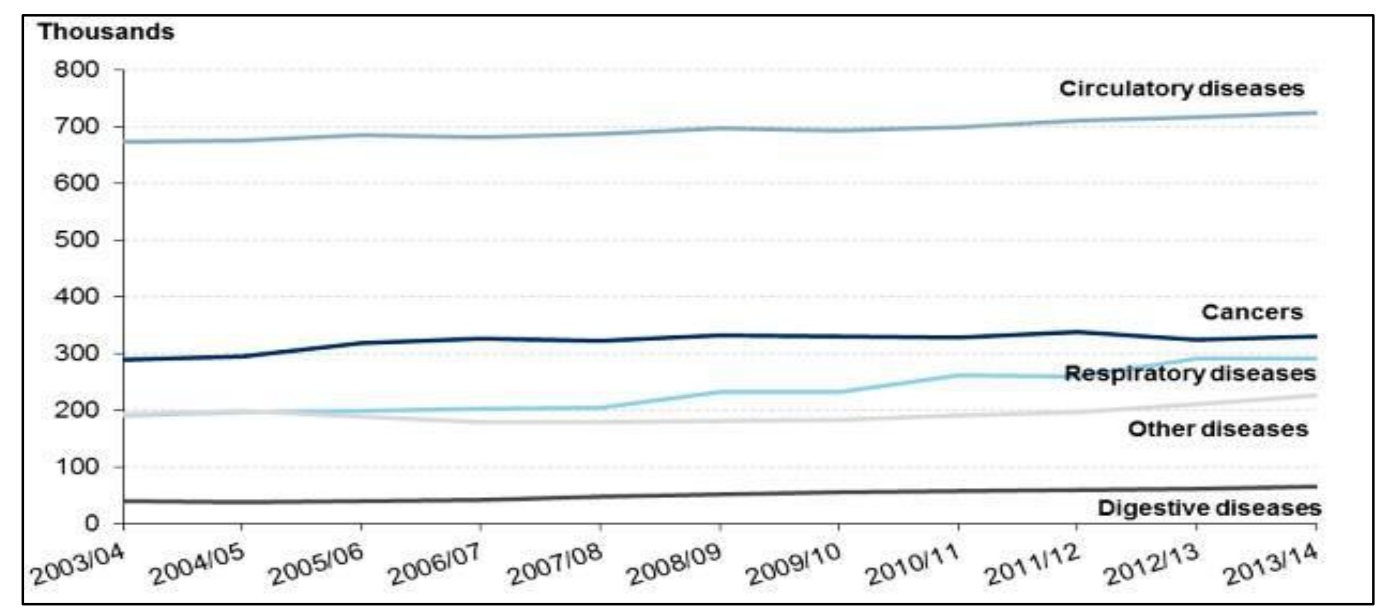

Figure 2: The NHS hospital admissions among adults aged 35 and over in England with primary diagnosis of disease which can be caused by SHS 2003/04 and 2013/13 (Niblet, 2015). 


\section{Metabolites of Tobacco Smoke}

Tobacco smoke contains approximately 7000 toxic chemicals including oxidative gases, heavy metals, carcinogenic chemicals, ciliary injuring substances and various other harmful substances (Avila-Tang et al., 2013). Figure 3 illustrates components of tobacco smoke and their respective metabolites. Tobacco is primarily metabolized in the liver, and to a smaller extent in the kidney and lungs. Enzymes such as cytochrome P450 2A6 (CYP 2A6), flavin monooxygenase 3 (FMO 3) and UDP-glucoronyltransferase (UGT) enhances the metabolism of tobacco. Furthermore, nicotine the main metabolite of tobacco is a psychoactive compound and it is the mediator of tobacco addiction. This is because it can cross the blood brain barrier as it has a pyridine and pyrrolidine ring which enhances its solubility (Thomas et al., 2011). Moreover, tobacco specific nitrosamines (TSNA), polycyclic aromatic hydrocarbons $(\mathrm{PAH})$ and volatile organic compounds (VOC) are metabolized to their respective by-products as illustrated in figure 3. Thus, in the early 1970, the international agency for research on cancer (IARC) understood that tobacco metabolites can be used as biomarkers to determine the level of SHS in different individuals (Yuan et al., 2014).

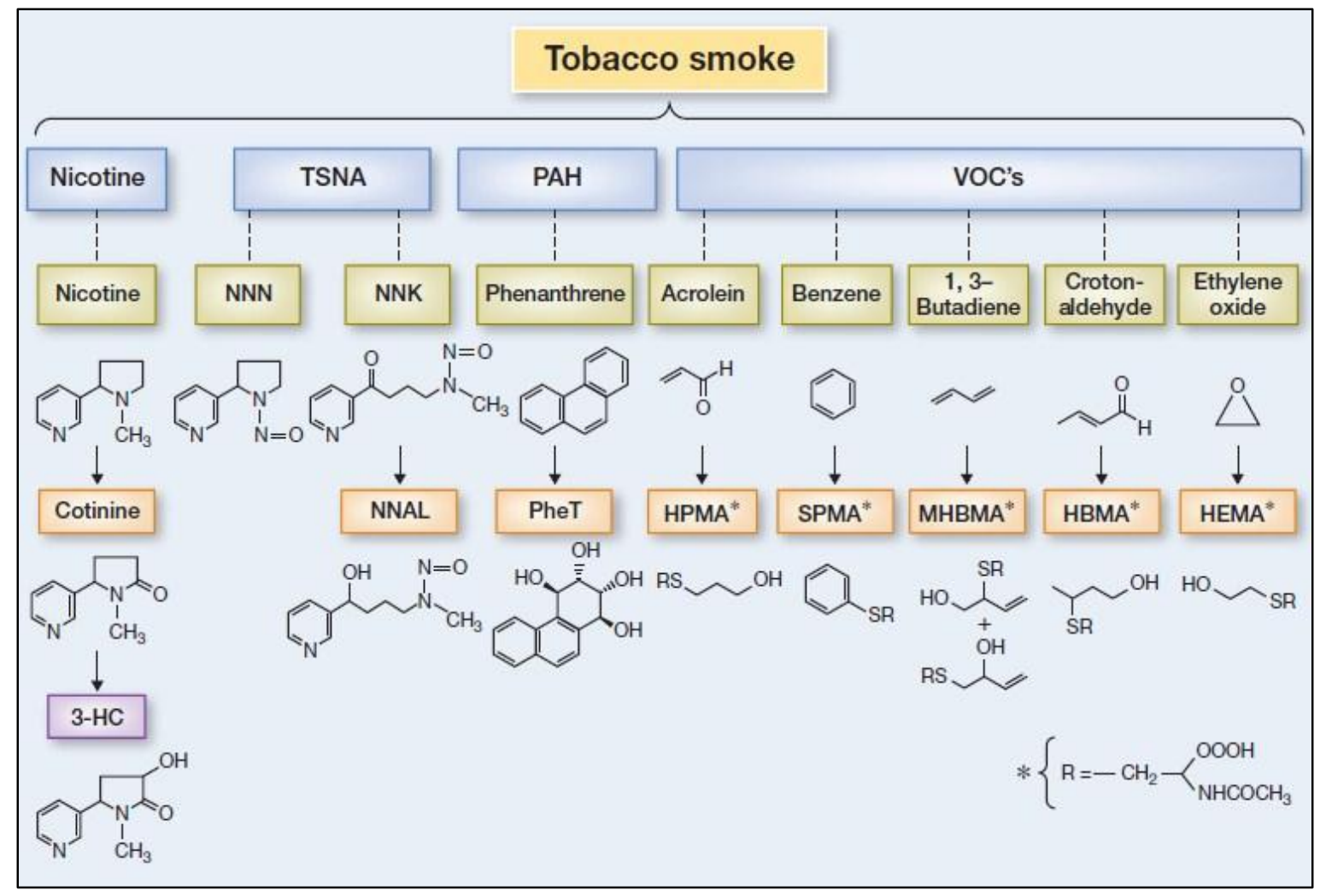

Figure 3: Metabolites of tobacco. Tobacco alkaloids are the active principal components in all tobacco products. Among the components of tobacco, nicotine is the most abundant ( $98 \%$ of the total alkaloids) tobacco metabolite (Yuan et al., 2014).

\section{Tobacco Metabolites Used as Tobacco-Specific Biomarkers}

A biomarker is desirable in quantitating systemic exposure to SHS in different individuals. Therefore, the national research council has proposed four criteria's which should be fulfilled so that a specific tobacco metabolite can be 
used as a valid biomarker to detect ETS (Florescu et al., 2009). Table 1 explains the four criteria's for tobacco biomarkers. Whereas, in table 2 presents the most ideal markers used to assess ETS exposure.

Table 1: The four criteria's proposed by national research council (Benowitz, 1999).

\section{Criteria's}
01. Should be unique or nearly unique so that other sources are minor in comparison
02. Should be easily detectable and have a reasonable half life
03. Should be emitted at similar rates for a variety of tobacco products
04 Should have a fairly constant ratio to other ETS components of interest under a range of environmental conditions encountered

Table 2: Biomarker used to detect environmental tobacco in passive smokers.

\begin{tabular}{|c|c|c|c|c|c|}
\hline Biomarker & Reference & Specificity & Sensitivity & $\begin{array}{l}\text { Duration after } \\
\text { exposure reflected }\end{array}$ & Comments \\
\hline Cotinine & Dhar, 2004 & High & High & 3-4 days & $\begin{array}{l}\text { Can be measured in urine, plasma, } \\
\text { saliva and hair }\end{array}$ \\
\hline Nicotine & $\begin{array}{l}\text { Yuan et al., } \\
2014\end{array}$ & High & High & Hours & $\begin{array}{l}\text { Short half-life ( } 2-3 \text { hours }) \\
\text { indicating that results are very } \\
\text { dependent on time of sampling; } \\
\text { saliva nicotine can be elevated by } \\
\text { local deposition of ETS. Plasma }\end{array}$ \\
\hline & & & & & $\begin{array}{l}\text { levels are very low. Urine levels } \\
\text { are highly influenced by urine } \\
\text { volume and pH. Hair measurement } \\
\text { is promising as a long term marker } \\
\text { of exposure. But analytical } \\
\text { techniques are relatively } \\
\text { expensive. }\end{array}$ \\
\hline
\end{tabular}




\begin{tabular}{|c|c|c|c|c|}
\hline $\begin{array}{l}\text { Carbon } \\
\text { monoxide } \\
(\mathrm{CO})\end{array}$ & $\begin{array}{l}\text { Hatsukamiet al., Low } \\
2010 \text {; } \\
\text { SRNT } \\
\text { subcommittee } \\
\text { on } \\
\text { biochemical } \\
\text { verification, } \\
2002\end{array}$ & Low & Hours & $\begin{array}{l}\text { Many environmental sources, CO } \\
\text { also produced by endogenous } \\
\text { metabolism. Only small changes in } \\
\text { CO levels are seen after ETS } \\
\text { exposure. Short half-life (4-5 } \\
\text { hours) limits its usefulness to } \\
\text { determine ETS exposure. } \\
\text { Sensitivity limited due to rapid } \\
\text { elimination. }\end{array}$ \\
\hline $\begin{array}{l}\text { Thiocyanate } \\
\text { (SCN) }\end{array}$ & $\begin{array}{l}\text { Jarvis et al., } \\
1987\end{array}$ & Low & Weeks & $\begin{array}{l}\text { Many dietary sources. Specifically } \\
\text { reliable for heavy smokers and not } \\
\text { for light smokers due to dietary } \\
\text { sources also contain SCN. }\end{array}$ \\
\hline $\begin{array}{l}\text { Aminobiphe } \\
\text { nyl- }\end{array}$ & $\begin{array}{l}\text { Hammod et } \\
\text { al., 1993; }\end{array}$ & Moderate & Months & $\begin{array}{l}\text { Levels in non-smoker may be } 10 \text { to } \\
20 \% \text { those of smokers.Analytical } \\
\text { techniques technicallydifficult. }\end{array}$ \\
\hline
\end{tabular}

haemoglobin Bartsch et al.,

1990

\begin{tabular}{|c|c|c|c|c|}
\hline $\begin{array}{l}\text { Benzo[a]pyrene- } \\
\text { DNA adduct }\end{array}$ & $\begin{array}{l}\text { Binkovaetal., Low } \\
\text { 1995; Van }\end{array}$ & Low & Probably months & $\begin{array}{l}\text { Analysis is technically difficult. } \\
\text { Difference between smokers } \\
\text { and non-smokers are found in } \\
\text { all studies }\end{array}$ \\
\hline
\end{tabular}

1994

PAH- Benowitz,199 $\quad$ Moderate $\quad$ Moderate 21 days $\quad$ Analysis is technically difficult

albumin $\quad 9$

Cotinine, the major metabolite of nicotine has a longer half-life (15 - 19 hours) in body fluids, and it remains stable throughout the day when compared to nicotine which oscillates (Florescuet al., 2009; Benowitz, 1996). In addition, it is very specific when compared to other markers, because it has a long elimination time and its levels are not affected by the other factors such as, environment factors and dietary intake (Yuan et al., 2014). Therefore, cotinine is known to be the best surrogate biomarker to assess the level of tobacco exposure in passive smokers (Flores, Liu \&Taroli, 2016; Haley, Axelard\& Tilton, 1983).

\section{Cotinine Detection in Biological Matrices}

The levels of cotinine present in biological fluids due to SHS is in low concentration, therefore assessing the level of risk due to tobacco smoke is a challenging task (Yuan et al., 2014).Thus, a range of analytical techniques such as; gas chromatography -MS (GC-MS), radioimmunoassay (RIA) and high performance liquid chromatography (HPLC) 
with UV/MS are being designed to detect cotinine. RIA is a sensitive method as it uses antibodies which bind to cotinine. However, it is not specific because the antibodies may bind to structures similar to cotinine in the sample of study which will result in a false positive analysis (Tricker, 2006). GC and HPLC are highly specific and sensitive methods because it separates the chemical using a column, and then measures that separated molecule using a detector. In this review, the development of different analytical techniques in four body fluids will be described.

\section{Salivary Cotinine Detection}

Salivary cotinine is commonly used for large population studies as it is a non - invasive technique which can be carried out quickly. Moreover, it can be used in studies where multiple sample collection is required. However, as it is $\mathrm{pH}$ dependent, standardized sample collection and storage is required for saliva cotinine measurements (Tricker, 2006).

Initially cotinine determination in saliva was performed by RIA, developed by Langone and his team in 1973. In this technique they used a radioactive tracer known as cotinine 4'carboxyllic acid molecule that covalently bound to ${ }^{125} \mathrm{I}$ probe, this complex then binds to the cotinine present in saliva. This is detected using an immuno-electrophoretic method (Haley, Axelrad \& Tilton, 1983; Matsukura et al., 1979). Later, in 1986 Bjercke and his coworkers proposed that by using monoclonal antibodies the specificity and sensitivity of cotinine detection can be increased 10 times to that of conventional RIA. Therefore, they used monoclonal antibodies to develop enzyme linked immunosorbent assays (ELISA) and a fluorescence immuno assay (FIA) (Benkirane et al., 1991). But, in 1987 he used polyclonal antibodies, which have shown a 100 - 1000 fold higher sensitivity compared to monoclonal antibodies (Bjercke, 1987). This technique was later opposed by Feyerabend and Russelll in 1990, because they observed that chromatography techniques were more sensitive and specific compared to immunoassays. Thus, his team proposed GC with nitrogen/phosphorus thermionic detection (GC-NPD) technique for chemical analysis and quantification of cotinine. This declaration was then confirmed by Watts and his fellow scientists in 1990, when they observed that there were no cross reactions that occurred, because the elements (nitrogen and phosphorus) in the cotinine molecule was itself used for detection (Matsumoto et al., 2010; Zuccaro et al., 1997; Watts et al., 1990). However, all the above mentioned methods are generally time consuming because sample extraction is done manually and they are expensive since they require trained expertise and costly reagents for equipment maintenance. Therefore, in 2009 Kataoka and his associates developed an automated in tube solid phase micro extraction (SPME) technique coupled with LC-MS. This extraction method is automated thereby reducing analysis time and carry over contamination because the extracted sample is directly injected to the chromatography column. Hence, it increases the precision and sensitivity of the analytical method (Kataoka et al., 2009; Floresceu et al., 2009; Elsert \& Pawliszyn, 1997). Figure 4 illustrates the experimental study carried out to prove SPME method. 


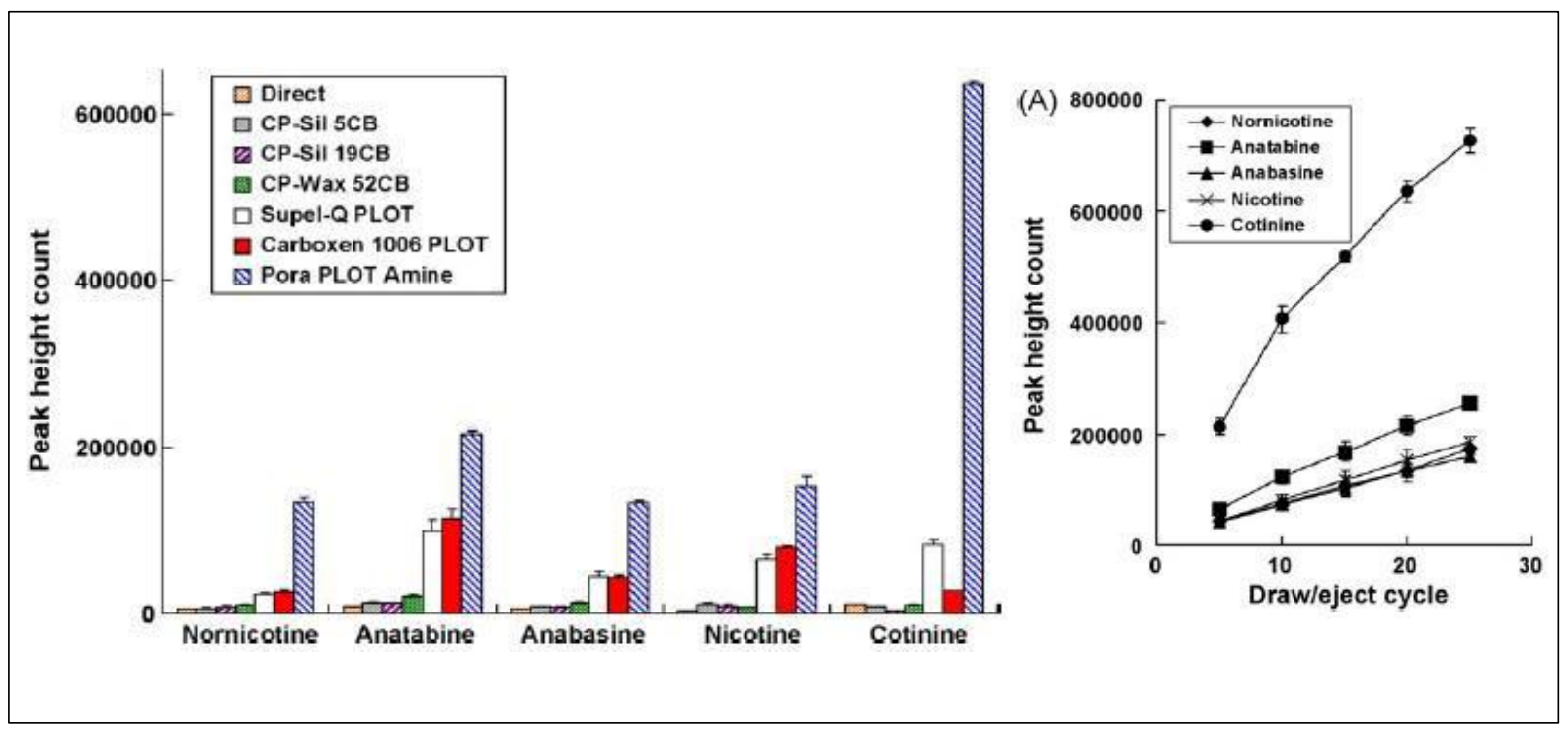

Figure 4: The Experimental study conducted by Kataoka and his team. The extraction was optimized by a number of factors like the stationary phase of the in tube SPME capillary column and number and volume of draw/eject cycles. In this study six different capillary columns were tested; CP-Sil 5CB, CP-Sil 19CB, CP-Wax 52CB, Supel-QPLOT Carboxen 1006 PLOTandPora PLOT Amine. Among these types Pora PLOT amine gave superior extraction efficiency because of its affinity to polar compounds and it had a greater adsorption surface. In addition the extraction was observed to be most efficient at $30 \mu \mathrm{L} / \mathrm{min}$ (Kataoka et al., 2009).

Although the method proposed by Kataoka and his team, reduced sample pretreatment analysis time, it could only be used to quantify large cotinine concentration. For this reason, in $2011 \mathrm{Ill}$ and his co-workers decided to modify the LC-tandem mass spectrometry method (LC-MS-MS) which was initially proposed by Bernet and his team at the center of disease control (CDC). They utilized electroscopy ionization (ESI) and atmospheric pressure chemical ionization (APCI) methods to increase the sensitivity and specificity for the determination of cotinine in low level exposure to ETS (Stragierowicz et al., 2013; Pitt, 2009). However, this technique was found to be highly prone to matrix suppression of ionization (Ill et al., 2011; Mallet, Lu \& Mazzeo, 2004; Liang et al., 2003; Matuszewski, Constanzer \& Charez-Engem, 1998). Therefore, in 2016 Ramdzan and his fellow workers established lab - on valve technique also known as third generation of flow injection analysis to automate sample pre-treatment (Ramos, 2012; Kataoka et al., 2009). As a result, they developed the bead injection- lab on valve (BI-LOV) for hyphenation of solid phase extraction (SPE) coupled to HPLC in the determination of cotinine. In addition, this technique is less time consuming and cost effective as sample pretreatment is automated. Table 3 illustrates a summary of certain salivary detection techniques.

Table 3: Summary of analytical techniques to detect salivary cotinine.

\begin{tabular}{|c|c|c|c|}
\hline Technique/ Assa y & $\begin{array}{l}\text { Limit of } \\
\text { Detection (LOD/ } \\
\mu \mathrm{g} / \mathrm{ml})\end{array}$ & $\begin{array}{l}\text { Limit of } \\
\text { Quantification } \\
(\mathrm{LOQ} \mu \mathrm{g} / \mathrm{ml})\end{array}$ & Reference \\
\hline RIA $\left({ }^{125} \mathbf{I},{ }^{3} \mathrm{H}\right)$ & $2.00 \times 10^{-3}$ & 0.37 & $\begin{array}{l}\text { Langone \& Van Vunakis, 1987; Langone } e t \\
\text { al., } 1973\end{array}$ \\
\hline
\end{tabular}


Shadiya Fawzul Ameer \& Mathi Kandiah / Detection of Cotinine in Passive Smokers Exposed...

\begin{tabular}{lllll}
\hline RIA $\left({ }^{3} \mathbf{H}\right)$ & $0.37 \times 10^{-3}$ & 0.2 & Haley, Axelard \& Tilton, 1983 \\
\hline RIA $\quad\left({ }^{\mathbf{1 2 5}} \mathbf{I}\right.$, & $\left.{ }^{\mathbf{3}} \mathbf{H}\right)$, & $0.50-1.50 \times 10^{-3}$ & 0.1 & Bjercke et al., 1986
\end{tabular}

ELISA, FIA

\begin{tabular}{llll}
\hline GC-NPD & $0.10 \times 10^{-3}$ & $10 \times 10^{-3}$ & Feyerabendet al., 1986 \\
\hline LC-MS/MS & $0.1 \times 10^{-3}$ & $50 \times 10^{-3}$ & $\begin{array}{l}\text { Matuszewski, Constanzer \& Charez-Engem, } \\
1998 .\end{array}$ \\
\hline SPME-HPLC/MS & $15-40 \times 10^{-2}$ & - & Kataoka et al., 2009 \\
\hline LC-API-MS/MS & $1.07 \times 10^{-3}$ & - & Smith et al., 2014; Bernet et al., 2009 \\
\hline GC-MS & $14.7 \times 10^{-3}$ & $10 \times 10^{-3}$ & Parzynski et al., 2008; Torano \& Van, 2003 \\
\hline LC-ESI-APCI-MS & $0.12 \times 10^{-3}$ & $>0.4 \times 10^{-3}$ & Stragierwicz et al., 2013 \\
\hline BI-LOV- $\mu$ SPE- & $15 \times 10^{-3}$ & $3.0 \times 10^{-3}$ & Ramdzan et al., 2016 \\
HILIC & & &
\end{tabular}

\section{Urinary Cotinine Detection}

Urinary cotinine detection is a non - invasive method that depends on urinary $\mathrm{pH}$ and rate of urine flow. Therefore, appropriate storage conditions should be given to get reliable results, since high temperature can cause thermal degradation of N-glucuronide and thus increasing urinary cotinine levels, resulting in false positive analysis. For instance, polypropylene-polyethylene sponge salisoft tubes are used for urine collection and it should be stored at $20^{\circ} \mathrm{C}$ (Tricker, 2006).

In the past urinary cotinine levels were detected using conventional RIA methods, however, as it lacked specificity, different analytical techniques were developed (Langone\& Van Vunakis, 1987; Knight et al., 1985; Langone, Gjika\& Van Vunakis, 1973). For instance, in 1991 Hariharan and Van Noord developed gas chromatography on capillary column coupled to nitrogen phosphorus detector (GC-NPD) method to overcome cross reactivity that could occur in RLA methods. However, GC-NPD was found to have a lower detection limit as they are affected by certain drugs such as Theophylline if present in sample (Matsumoto et al., 2010; Kuo, Yang \& Chiu, 2001; Feyerabend\&Russel, 1990). Therefore, in 1998 Oddoze and his team developed reversed phase HPLC method paired with UV detector (RH-HPLC-UV), which is applicable for epidemiological studies. Since, these preliminary HPLC techniques can be non-specific as it can interfere with caffeine if present in sample (Kim et al., 2004; Knight et al., 1989; Langone, Gijka \& Van Vunakis, 1973). As a result, compound specific methods such as mass spectrometry (HPLC - atmospheric pressure chemical ionization tandem mass spectrometry (HPLC-API-MS) which is more specific was developed in 1997 by Bernet and his friends (Tuomiet al., 1999; Rustemeieret al.1993; Mc Manus et al., 1990). Figure 5 illustrates the comparison between compound specific detection and compound nonspecific detection. 


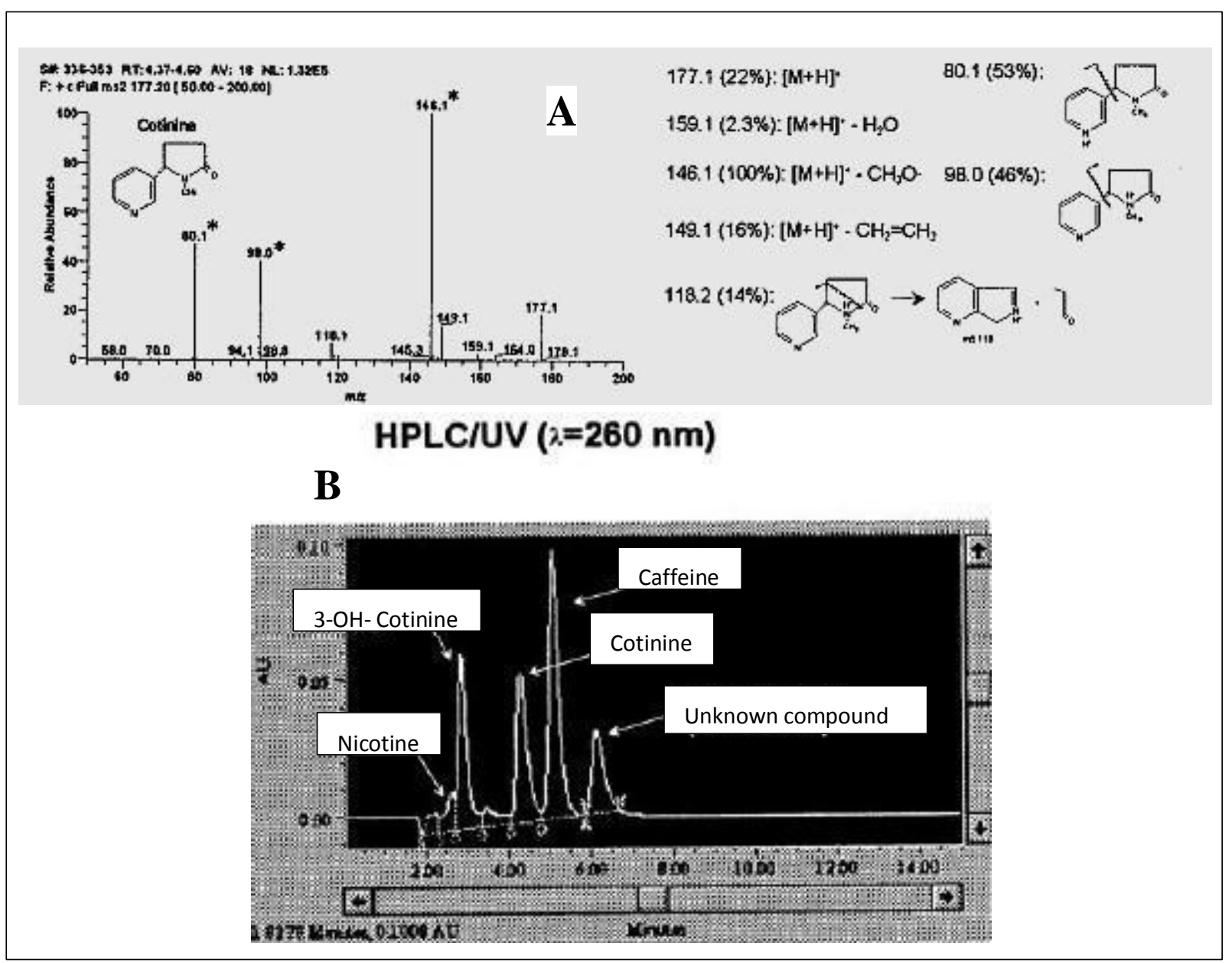

Figure 5: (A) Compound specific detection gives rise to peaks only specific to elements present in cotinine. Whereas, compound non-specific detection (B) can have peaks for other components present in ETS such as caffeine (Tuomiet al., 1999).

However, since all of the above techniques are usually time-consuming in sample pretreatment Kataoka and his coworkers developed an automated in tube solid phase extraction coupled to HPLC and LC-MSMS in 2009. This technique is selective, sensitive and allows easy monitoring of ETS in passive and active smokers. Whereas, in 2010 Apinan and her team designed a simpler, sensitive and selective technique to detect cotinine in a single step analysis. This method was based on HPLC electrospray ionization tandem mass spectrometry (HPLC-ESI-MS-MS). Although these techniques did not require sample pretreatment, it was highly likely that contamination could occur, giving rise to inaccurate results. Hence, in 2013 Iwai and his team used micro-extraction by packed sorbent coupled to GC-MS (MEPS-GC-MS) technique to study passive smokers in ETS. This technique increased sensitivity as it was directly subjected to GC-MS without sample evaporation. Moreover, in $2016 \mathrm{Li}$ and his team developed liquid-liquid micro extraction (LLME) combined with GC-MS to avoid any cross contamination. Later that year, Carrizo and his team redesigned the mass spectrometry technique, desorption electrospray ionization (DESI) and the direct analysis in real time (DART) techniques proposed by Mc Ewen in 2005. They coupled this atmospheric pressure solid analysis probe (ASAP) technique to a high resolution quadruple time of flight mass spectrometry (Q-TOF-MS) technique in order to detect and study the specific structure and shape of nicotine and their major metabolites - cotinine in biological samples. This technique is was proved to be a highly efficient and sensitive method because it does not involve and sample pre-treatment and the sample can be directly injected in to the ionization chamber (Carrizo et al.,2016). Table 4 summarizes the analytical techniques to detect urinary cotinine. 
Table 4: Analytical methods to detect urinary cotinine.

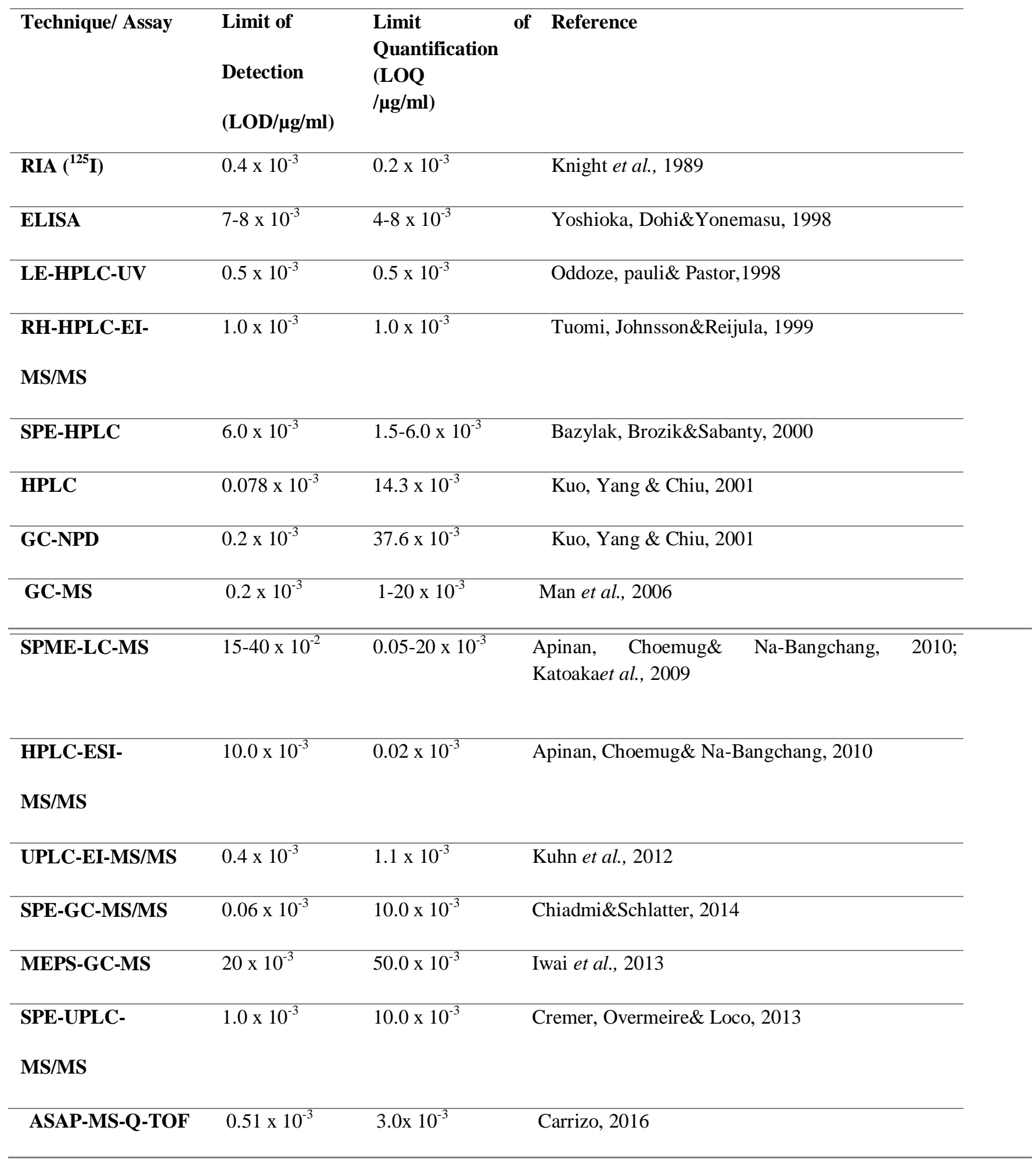




\section{Serum Cotinine Detection}

In passive smokers, cotinine concentrations in plasma increases during the first 4-6 hours after exposure and then it gradually plateaus down (Teeuwen, Alder \& Van Rossum, 1989; Feyerabend, Ing\& Russell, 1985). Therefore, the best time to collect blood samples is in the mid afternoon as the cotinine levels remain almost in a steady state. This can then be stored at $37^{\circ} \mathrm{C}$ for 6 weeks, as serum cotinine is stable at normal body temperature (Tricker, 2006; Fouldset al., 1994).

Methods for assessing cotinine in passive smokers have developed over the past two decades. Initially, in the early 1980s RIA techniques were used to detect serum cotinine, but this technique has a $0.3 \%$ chance of cross reactivity with other tobacco metabolites producing inaccurate results (Watts et al., 1990; Langone\& Van Vunakis, 1987; LangoneGjika\& Van Vunakis, 1973). Hence, in 1989 Jacob and his team designed an improved gas chromatographic method for quantification of cotinine. In this method they used 1-butanol instead of methylene chloride to extract cotinine, since this results in less emulsion formation and cleaner separation layers. However, in 1997, the Third National Health and Nutrition Examination Survey (NHANES 111) stated that LC-MS-MS techniques are more suited for analyzing low cotinine concentrations when compared to GC-MS techniques. Since, serum cotinine levels below $\geq 10 \mu \mathrm{g} / \mathrm{L}$ will not be detected using capillary GC-MS (Bernetet al., 1997; Watts et al., 1990; Davis, 1986). Therefore, that year Bernet and his team designed a HPLC technique coupled to atmospheric pressure chemical ionization tandem mass spectrometry (API MS-MS). However, in 2002 Shin and his colleagues observed that APIMS-MS technique did not produce reliable results when the serum samples were in an alkaline state. Therefore, they developed an idea of concentrating the sample using nitrogen stream and directly injecting it to the GC-MS-selected ion monitoring (GC-MS-SIM) column. This proved to be a simple and convenient method, that and can be learned easily by unexperienced individuals. All the above mentioned techniques required large sample volumes and sample pretreatment prior to analysis (Nakajima et al., 2000). Thus, in 2005 Chang and his team developed a rapid, sensitive and cost effective technique, utilizing microdialysis sample extraction coupled with HPLC- UV detector. Sample preparation using microdialysis helps to continuously monitor the samples and reduce the chances of fluid loss. But further research provides more sensitive chromatography techniques. For instance, in 2012, Xu and Fan decided to study the sensitivity of cotinine using micellar electrokinetic chromatography (MEKC), combined with on line concentration technique, cation selective exhaustive injection (CSEI) and sweeping. The LOD was quantified using ultraviolet absorbance detection and it was $0.2 \mathrm{ng} / \mathrm{ml}$. Therefore, this method was proven to be successful. In addition, in 2013 Liu and his associates designed laminated analytical device (LPAD) with origami enabled chemiluminescence immunoassay to detect cotinine in SHS. This device was then fabricated by a craft-cutter to define flow channels and then laminated. This was done to improve the reliability of results and simplicity of the technique. This method proved to be cost effective and sensitive. Moreover, in 2014 Dunlop and his colleagues designed a LC-MS-MS technique using cotinine $\mathrm{d}_{3}$ as an internal standard couple to SPE to study large populations within a short period of time. The specificity and sensitivity of the results increased as cotinine quantification was done using electrospray ionization with multiple reaction monitoring. This technique was better than the other LC-M-MS techniques as the sample preparation and quantification was all one in a single analysis. Table 5 summarizes the analytical techniques used to detect serum cotinine over the years. 
Table 5: Summary of analytical methods to detect serum cotinine.

\begin{tabular}{|c|c|c|c|}
\hline Technique/ Assay & $\begin{array}{l}\text { Limit of Detection } \\
\qquad(\mathrm{LOD} \mu \mathrm{g} / \mathrm{ml})\end{array}$ & $\begin{array}{c}\text { Limit of } \\
\text { Quantification } \\
(\text { LOQ } \mu \mathrm{g} / \mathrm{ml})\end{array}$ & Reference \\
\hline RIA $\left({ }^{125} \mathbf{I},{ }^{3} \mathrm{H}\right)$ & $2.00 \times 10^{-3}$ & $2.00 \times 10^{-3}$ & Langone\& Van Vunakis, 1987 \\
\hline RIA $\left({ }^{3} \mathbf{H}\right)$ & $0.37 \times 10^{-3}$ & $1.0 \times 10^{-3}$ & Haley, Axelard\& Tilton, 1983 \\
\hline RIA $\left({ }^{125} I\right)$ & $0.3 \times 10^{-3}$ & $1.0 \times 10^{-3}$ & Knight et al., 1985 \\
\hline RIA $\left({ }^{125} \mathrm{I},{ }^{3} \mathrm{H}\right)$, ELISA, FIA & $0.50-1.50 \times 10^{-3}$ & $0.50-1.5 \times 10^{-3}$ & Bjerckeet al., 1986 \\
\hline GC-NPD & $0.10 \times 10^{-3}$ & $0.1 \times 10^{-3}$ & Feyerabend, 1987 \\
\hline HRGC-NPD & $0.2 \times 10^{-3}$ & $0.5-5.0 \times 10^{-3}$ & Jacob, Wilson \&Benowitz, 1989 \\
\hline Capillary GLC/NPD & $0.1 \times 10^{-3}$ & $0.1 \times 10^{-3}$ & Bernetet al., 2009 \\
\hline HPLC-API-MS MS & $<0.1 \times 10^{-3}$ & $<0.1 \times 10^{-3}$ & Bernetet al., 2009; Bernetet al., 1997 \\
\hline HPLC-ESI-MS-MS & $0.5 \times 10^{-3}$ & $0.5 \times 10^{-3}$ & Bernetet al., 2009 \\
\hline LLE-GC-MS & $0.16 \times 10^{-3}$ & $1.25 \times 10^{-3}$ & James, Tizabi\& Taylor, 1998 \\
\hline LLE-GC-MS-SIM & $1.0 \times 10^{-3}$ & $1.0 \times 10^{-3}$ & Shin et al., 2002 \\
\hline HPLC-UV & 0.01 & 0.05 & Chang et al., 2005 \\
\hline SPE-LC-ESI-MS-MS & $0.13 \times 10^{-3}$ & $0.2 \times 10^{-3}$ & Dunlop et al., 2014 \\
\hline
\end{tabular}

\section{Hair Cotinine Detection}

Analysis of cotinine in human hair provides reliable information on ETS over a long time period. However, it can be affected by chemicals used in hair dyes, and the melanin content (Umetsu, 1993; Kintz\&Mangin, 1993). The cut off value to distinguish between a smoker and non-smoker is $>2$ ng cotinine/mg of hair, which can be analysed by a number of different analytical methods (Kintz, Ludes\&Mangin, 1992). These techniques differ in either the washing or extraction steps. As a range of solvents such as, ethanol and dichloromethane are used to the wash hair to remove passive absorbed cotinine prior to analysis (AlDelamiy, 2002). Upon washing the samples are subjected to neutralization using concentrated hydrochloric acid and then they are analyzed using a respective analytical technique (Tricker, 2006).

In the past, GC and radioimmunoassay (RIA) techniques were used to detect cotinine, however, these techniques are expensive and cannot be used in routine laboratories. In addition, RIA measurement of cotinine can cause cross reactivity, especially with other cotinine and nicotine metabolites (Torano\& Van Kan, 2003; Dimish-Ward et al., 
1997). Therefore, in 2001 Mahoney and Al-Delaimy used solid phase extraction, reversed-phase high performance liquid chromatography (SPE-RH-HPLC/ECD) coupled with electrochemical detection, because it gave a better LOD $(0.05 \mathrm{ng} / \mathrm{mg})$ than HPLC coupled to UV detection. But RH-HPLC-ECD or HPLC/ECD are not used in common laboratories, and the sorbents used in SPE to retain the analytes result in low sensitivity and specificity as the binding is not specific. Thus, SPE coupled with molecular imprinted polymer (MISPE) enhanced the sensitivity of the HPLC technique (Yang et al., 2007; Mahoney \& Al-Delaimy, 2001). Although the sensitivity of HPLC increased in terms of extraction it was not capable of analyzing minute cotinine concentrations and large number of sample in a single analysis. Hence, in 2013 Tsuji and his co-workers developed HPLC/UV to column switching method which was 12.9 to 16.9 more sensitive than preliminary HPLC techniques. Figure 6 illustrates the increased sensitivity of sample analysis using HPLC/UV couple with column switching method and other HPLC techniques. Thereafter, in 2016 Pradel and his partners, introduced spectroscopic methods using non-linear multi-photon lasers for ultrasensitive detection, separation and identification of cotinine. In this technique extraction method was very sensitive as it used compact, portable capillary-or microchip based separation. Table 6 illustrates a summary of the techniques proposed above for hair cotinine.

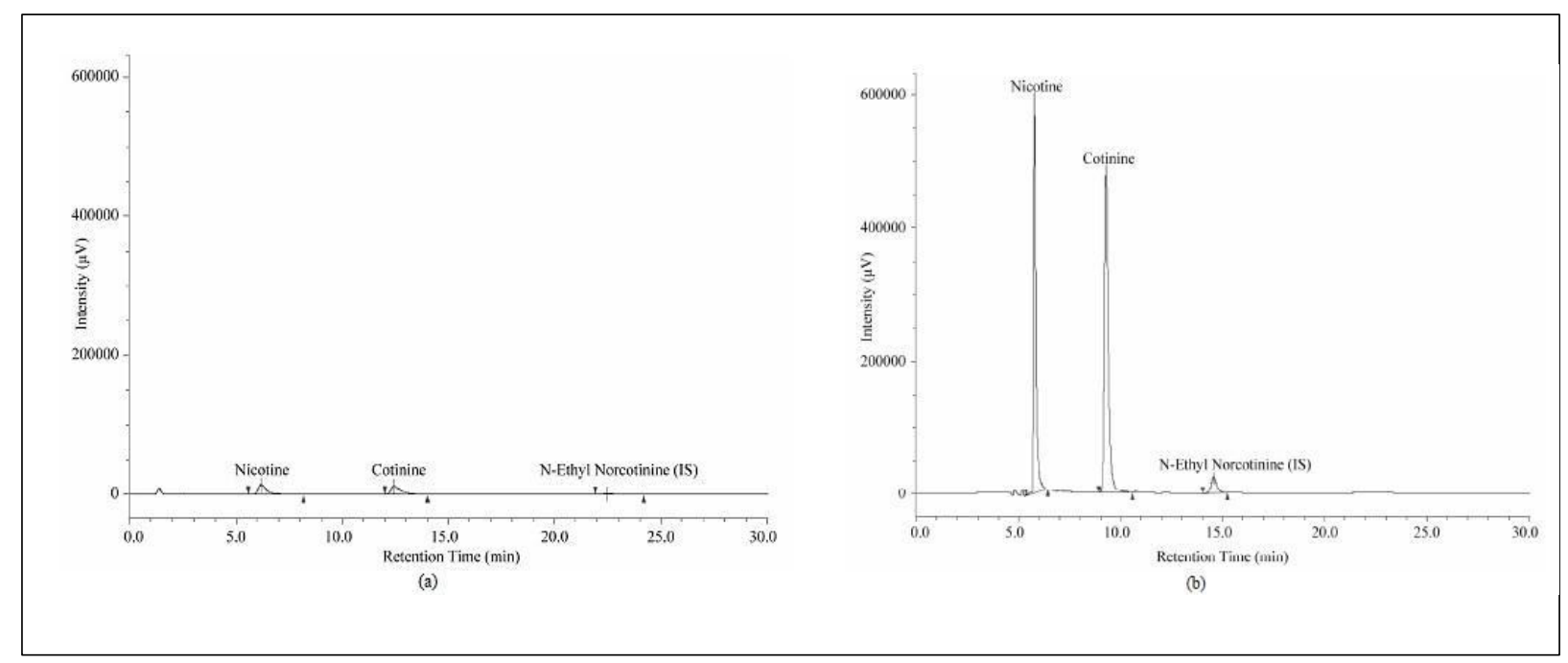

Figure 6: Chromatograms obtained for hair cotinine and nicotine sample using different HPLC techniques. (a)Results obtained from preliminary HPLC techniques, which lack sensitivity when analyzed for minute cotinine levels. (b) Results obtained from HPLC/ UV coupled with column switching, which had a greater sensitivity than the other HPLC techniques (Tsuji et al., 2013).

Table 6: Summary of hair cotinine detection techniques.

\begin{tabular}{|c|c|c|c|}
\hline Technique/ Assay & $\begin{array}{l}\text { Limit of Detection } \\
\text { (LOD ng/mg) }\end{array}$ & $\begin{array}{c}\text { Limit of } \\
\text { Quantification } \\
\text { (LOQ ng/mg) }\end{array}$ & Reference \\
\hline
\end{tabular}

\begin{tabular}{lccc}
\hline RIA & 0.1 & 0.3 & Ellopouloset al., 1994 \\
\hline GC-MS & 0.01 & 0.60 & Torano\& Van Kan, 2003 \\
\hline SPE-RH-HPLC/ECD & 0.05 & 0.1 & Mahoney \& Al-Delaimy,2001
\end{tabular}




\begin{tabular}{lccc}
\hline MISPE-HPLC & 0.2 & 0.5 & Yang et al., 2007 \\
\hline LLE-GC/MS & 0.02 & - & Kim et al., 2008 \\
\hline GC-NPD & 0.2 & - & Kim et al., 2009 \\
\hline HPLC/UV & 0.08 & 0.1 & Tsuji et al., 2013 \\
\hline
\end{tabular}

\section{Summary and future perspectives}

Cotinine, the first metabolite of nicotine is the best biomarker to indicate tobacco smoke exposure. This is because it has a long half - life and not affected by other environmental factors. Various methods are such as, HPLC, GC, colorimetric assays and RIA's are designed and used in developed countries, in order to setup smoke free regulations in public, indoor areas and workplaces. Cotinine present in each body fluid varies in concentration, therefore the most reliable body fluid should be chosen for population studies.

Urine cotinine was known to be a gold standard for ETS exposure measurement, therefore it was used widely for all epidemiological studies. But it was affected by inter-individual variability in cotinine excretion levels for similar exposures. In addition it had a short half-life of 20 hours. Salivary cotinine is subjected to similar drawbacks, plus saliva samples were prone to be concentrated by salivary glands giving rise to false high estimates of cotinine in saliva. Despite it being a non-invasive technique. Therefore, assessing hair cotinine levels is a better choice as it is less affected by daily changes in the ETS exposure (due to the slow growth rate of hair), body metabolisms and it provides a long term history because $1 \mathrm{~cm}$ of hair represent a month's tobacco exposure. However, hair cotinine detection cannot be done between different races and ethnic groups, because melanin content play an important role. In that case the next best biological matrix would be saliva as it is a non-invasive method and not affected by and external factors like hair dyes. Thus, different analytical technique are being developed for detection of cotinine in each body fluid, table 7 illustrates the summary of the best available techniques for each body fluid.

In the future, genomic based methods and modernized immunological methods using mutant single chain Fv fragments are to be designed to detect cotinine in dried blood samples. This is mainly because it reduces the time required for cotinine detection and produces more accurate results, since it does not depend on sample collection and storage. In addition, micro extraction methods like, dispersive liquid - liquid micro - extraction (DLLEM) techniques are to be developed enhance the sensitivity of the test results. For instance DLLEM technique is coupled to injection port silylation (IPS) to detect cotinine using GC - MS.

Table 7: Summary of the most efficient, sensitive techniques for each body matrix.

\begin{tabular}{lcccc}
\hline & Saliva & Serum & Urine & Hair \\
\hline Technique & BI-LOV- $\mu$ SPE-HILIC & HPLC-UV & SPME-LC-MS & MISPE-HPLC \\
\hline Internal & Acetonitrile (ACN) & Acetonitrile (ACN) & Methanol & Acetonitrile \\
Standard & & & (ACN) \\
(IS) & & & \\
\hline Extraction & Automatic micro solid Micro-dialysis & Automated & Solid phase \\
Method & phase extraction & solid phase & extraction \\
& & micro & \\
& & extraction &
\end{tabular}


Proceeding of the $2^{\text {nd }}$ International Conference on Bioscience and Biotechnology, Vol. 2, 2017, pp. 87-107

\begin{tabular}{|c|c|c|c|c|}
\hline LOD & $15.0 \times 10^{-3} \mu \mathrm{g} / \mathrm{ml}$ & $0.01 \mu \mathrm{g} / \mathrm{ml}$ & $\begin{array}{c}15.0-40.0 \mathrm{x} \\
10^{-2} \mu \mathrm{g} / \mathrm{ml}\end{array}$ & $0.2 \mathrm{ng} / \mathrm{mg}$ \\
\hline LOQ & $3.0 \times 10^{-3} \mu \mathrm{g} / \mathrm{ml}$ & $0.05 \mu \mathrm{g} / \mathrm{ml}$ & $\begin{array}{c}0.05-20.0 \mathrm{x} \\
10^{-3} \mu \mathrm{g} / \mathrm{ml}\end{array}$ & $0.5 \mathrm{ng} / \mathrm{mg}$ \\
\hline Advantage & $\begin{array}{l}\text { Automated sample } \\
\text { pretreatment to reduce } \\
\text { pretreatment time and } \\
\text { volume of reagents used. } \\
\text { Higher sensitivity } \\
\text { because hydrophilic } \\
\text { interaction liquid } \\
\text { chromatography column } \\
\text { is used. ACN enhances } \\
\text { the sensitivity and } \\
\text { retention efficiency. }\end{array}$ & $\begin{array}{l}\text { The samples of microdialyste are } \\
\text { protein free making it possible } \\
\text { for direct coupling of the } \\
\text { microdialysis to the liquid } \\
\text { chromatographic graphic analysis } \\
\text { with no sample cleanup required. } \\
\text { This is a simple, rapid and cost } \\
\text { saving technique. }\end{array}$ & $\begin{array}{l}\text { SPME- } \\
\text { automated } \\
\text { extraction } \\
\text { method, } \\
\text { reduces } \\
\text { sample } \\
\text { analysis time, } \\
\quad \text { better } \\
\text { precision and } \\
\text { sensitivity. }\end{array}$ & $\begin{array}{l}\text { Selective } \\
\text { extraction, as the } \\
\text { molecular } \\
\text { imprinted } \\
\text { polymer has a } \\
\text { recognition site } \\
\text { to which the } \\
\text { cotinine } \\
\text { molecule can } \\
\text { bind. }\end{array}$ \\
\hline
\end{tabular}

\section{References}

Al-Demaiy, W. K., Crane, J \& Woodward, A., 2002, Is the hair nicotine level a more accurate biomarker of environmental tobacco smoke exposure than urine cotinine. Journal of Epidemiological Community Health, 56, 66 71.

Apinan, R., Choemug, A \& Na-Bangchaog, K., 2010, A sensitive HPLC-ESI-MS-MS method for the development of cotinine in urine. Journal of Chromatographic Science, 48, 460-466.

Avila-Tang, E., Al-Delaimy, W.K., Ashley, D.L., Benowitz, N., Bernet, J. T., Kim, S., Samet, J.M \&

Hecht, S.S., 2013, Assessing second hand smoke using biological markers. Tobacco Control, 22, 164 -71.

Bartsch, H., Caporaso, N., Coda, M., Kadlubar, F., Malaveille, C., Skipper, P., Talaska, G., Tannenbaum, S. R \&Vineis, P., 1990, Carcinogen hemoglobin adducts urinary mutagenicity, and metabolic phenotype in active and passive cigarette smokers. Journal of National Cancer Institute, 82, 1826 -1831.

Bazylak, G., Brozik, H \&Sabanty, W., 2002, HPTLC, screening assay for urinary cotinine as biomarker of environmental tobacco smoke exposure among male adolescents. Journal of Pharmaceutical and Biomedical analysis, 24, $113-123$.

Beckett, A.H \&Triggs, E.J., 1966, Determination of nicotine and its metabolites, cotinine in urine by gas chromatography. Journal of Chromatography B, 211, 1415 - 1417.

Benkirane, S., Nicolas, A., Marie-Madeleine, G \&Siest, G., 1991, Highly Sensitive immunoassay for the detection of cotinine in serum and saliva: Comparison between RIA and aAvidin-Biotin ELISA.

European Journal of Clinical Chemistry, 29, $405-409$. 
Benowitz, N. L., 1999, Biomarkers of environmental tobacco smoke exposure, Environmental Health Perspectives, $107,349-355$.

Benowitz, N.L., 1996, Cotinine as a biomarker of environmental tobacco smoke exposure. Epidemiological review, $18,188-204$.

Bernet, T.J., Jacob, P., Holiday, B.D., Benowitz, L.N., Sosnoff, S.C., Dogi, V.M., Feyerabend, C., Aldous, M.K., Sharifi, M., Kellogg, D.M \&Langman, J.L., 2009, Interlaboratory comparability of serum cotinine measurements at smoker and non-smoker concentration levels: A round robin study. Nicotine and Tobacco Research, 11, 1458 - 1466.

Binkova, B., Lewtas, J., Miskova, I., Lenicek, J \&Sram, R., 1995, DNA adducts and personal air monitoring of carcinogenic polycyclic aromatic hydrocarbons in an environmentally exposed population.

Carcinogenesis, 16, 1037 - 1046.

Bjercke, R. J., Cook, G. \&Langone, J. J., 1987, Comparison of monoclonal and polyclonal antibodies to cotinine in non-isotopic and isotopic immunoassays. Journal on immunological methods, 96, 239 - 246.

Bjercke, R. J., Cook, G., Rychlik, N., Gjika, H.B., Van Vunakis, H. \&Langone, J. J., 1986, Stereospecific monoclonal antibodies to nicotine and cotinine and their use in enzyme linked immunosorbent assay.

Journal on Immunological Methods, 90, 203 - 213.

Bratan, A., Mincea, M. M., Lupsa, I.R., Pirtea, G.M \&Ostafe, V., 2014, Assessment of nicotine for second hand smoker exposure in some public places in Romania by UPLC-MS. Chemistry Central Journal, 8, 1 -

7.

Carrizo, D., Nerin, I., Domeno, C., Alfaro, B \&Nerin, C., 2016, Direct screening of tobacco indicators in urine and saliva by atmospheric pressure solid analysis probe coupled to quadruple-time of flight mass spectrometry (ASAPMS-Q-TOF). Journal of Pharmaceutical and Biomedical Analysis, 124, 149 - 156.

Chang, Y.L., Tsai, P.L Chou, Y.C., Tien, J.H \& Tsai, T.H., 2005, Simultaneous determination of nicotine and its metabolite, cotinine in rat blood and brain tissue using microdialysis coupled with liquid chromatography: Pharmacokinetic Application. Journal of Chromatography A, 1080, 152 - 157.

Chiadmi, F \&Schlatter, J., 2014, Simultaneous determination of cotinine and trans-3-hydroxycotinine in urine by automated solid-phase extraction using gas chromatography mass spectrometry. Biomedical Chromatography, 28, $453-458$.

Cremer, D.K., Overmeire, V.I \& Loco, V.J., 2013, On-line solid phase extraction with ultra-performance liquid chromatography and tandem mass spectrometry for the detection of nicotine, cotinine and trans-3'hydroxycotinine in urine to strengthen human bio monitoring and smoking cessation studies, Biomedical Chromatography. 76, 126 133.

Davis R.A., 1986, The determination of nicotine and cotinine in plasma, Journal of Chromatographic. 24, $134-41$.

Dhar, P., 2004, Measuring tobacco smoke exposure: quantifying nicotine/cotinine concentration in biological samples by colorimetry, chromatography and immunoassay methods. Journal of Pharmaceutical and Biomedical Analysis, 35, $155-168$.

Dimish-Ward, H., Gee, H., Brauer, M \& Leung, V., 1997, Analysis of nicotine and cotinine in the hair of hospitality workers exposed to environmental tobacco smoke. Journal of Occupational Environment, 39, 945 - 948.

Dunlop, J.A., Clunie, I., Stephen, W.S.D \& Allison, J.J., 2014, Determination of Cotinine by LC-MS-MS with automated solid phase extraction. Journal of Chromatographic Science, 52, 351 - 356. 
Ellopoulos, C., Klein, J., Phan, M.K., Knle,B., Greenwald, M., Chitayat, D \&Koren, G., 1994, Hair concentrations of nicotine and cotinine in women and their new born infants. Journal of the American Medical Association, 271, 621 623.

Elsert, R \&Pawliszyn, J., 1997, Automated in-tube solid phase micro-extraction coupled to high performance liquid chromatography. Analytical Chemistry, 69, 3140 - 3147.

Feyerabend, C., 1987, Determination of nicotine in physiological fluids by gas chromatography. Environmental Carcinogenesis Methods of Analysis and Exposure Measurement, 9, 299 - 307.

Feyerabend, C \& Russell, M.A., 1990, A rapid gas-liquid chromatographic method for the determination of cotinine and nicotine in biological fluids. Journal of pharmacy and pharmacology, 42, 450 - 452.

Feyerabend, C., Bryant, A., Jarvis, M. J. \& Russell, M. A. H., 1986, Determination of cotinine in biological fluids of non-smokers by packed column gas-liquid chromatography. Journal of Pharmacy and Pharmacology, 38, 917 - 919. Feyerabend, C., Ings, R.M.J \& Russell, M.A.H., 198, Nicotine Pharmacokinetics and its application to intake from smoking. Journal of Clinical Pharmacology, 19, 239 - 47.

Flores, M. R., Liu, B \&Taroli, E., 2016, Association of serum cotinine levels and lung cancer mortality in non smokers. Carcinogenesis, 31, 212 -241.

Florescu, A., Ferrence, R., Einarson, T., Selby, P., Solidin, O \&Koren, G., 2009, Methods of quantification of exposure to cigarette smoking and environmental tobacco smoke: Focus on developmental toxicology. National Institute of Health, 31, $14-30$.

Foulds, J., Feyerabend, C., Stapleton, J., Jarvis, M.J \& Russell, M.A.H., 1994, Stability of nicotine and cotinine in unfrozen plasma. Journal Smoking Related Disorders, 5, 41 - 44.

Haley, N. J., Axelrad, C. M. \& Tilton, K. A., 1983, Validation of self-reported smoking behavior: biochemical analyses of cotinine and thiocyanate. American Journal of Public Health, 73, 1204 - 1207.

Hammond, S. K., Coghlin, J., Gann, P. H., Paul, M., Taghizadeh, K., Skipper, P.L \&Tannenbaum, S. R., 1993, Relationship between environmental tobacco smoke exposure and carcinogen-hemoglobin adducts levels in nonsmokers. Journal of National Cancer Institute, 85, $474-478$.

Hariharan, M \& Van Noord, T., 1991, Liquid chromatographic determination of nicotine and cotinine in urine from passive smokers: Comparison with gas chromatography with a nitrogen phosphorus specific detection. Clinical Chemistry, 37, $1276-80$.

Hatsukami, O. K., Ktlyar, M., Hertsgaard, L.A., Zhang, Y., Carmella, S. G., Jensen, J. A., Allen, S. S., Shields, P. G., Murphy, S. E., Stepanov, I \& Hecht, S. S., 2010, Reduced nicotine content cigarettes: effects on toxicant exposure, dependence and cessation. National Institute of Health, 105, 343 - 55.

Ill, J. P., Yu, L., Duan, M., Ramos, L., Yturralde, O \&Benowitz, L. N., 2011, Determination of Nicotine metabolites, cotinine and Trans-3'-hydroxycotinine in biological fluids of smokers and non-smokers using liquid chromatography tandem mass spectrometry: Biomarker for tobacco smoke exposure and for phenotyping cytochrome P450 $2 \mathrm{~A} 6$ activity. Journal of Chromatography B Analytical Technology Biomedical Life Science, 879, 267 - 276.

Iwai, M., Ogawa, J., Hattori, H., Zaitsu, K., Istill, A., Suzuki, O \& Seno, H., 2013, Simple and rapid assay method for simultaneous quantification of urinary nicotine and cotinine using microextraction by packed sorbent and gas chromatography mass spectrometry. Journal of Medicine, 75, 255 - 261.

Jacob, P., Wilson, M \&Benowitz, N.L., 1989, Improved gas chromatographic and cotinine in biological fluids. Journal of Chromatography B, 222, $61-70$. 
Jarvis, M. J., Tunstall-Pedoe, H., Feyeraband, C., Vesey, C \&Saloojee, Y., 1987, Comparisons of tests used to distinguish smokers from non-smokers. American Journal of Public Health, 77, 1435 - 1438.

Jamaes, H.,Tizabi, Y \&Tay, R., 1998, Rapid methods for the simultaneous measurement of nicotine and cotinine in urine and serum by gas chromatography - mass spectrometry. Journal of Chromatography B, 708, 87 - 93.

Kataoka, H., Inoue, R., Yagi, K. \& Saito, K., 2009, Determination of nicotine, cotinine and related alkaloids in human urine and saliva by automated in tube solid-phase micro extraction coupled with liquid chromatography massspectrometry. Journal of Pharmaceutical and Biomedical Analysis, 49, 108 - 114.

Kim, H., Lim, Y., Lee, S., Park, S., Kim, C., Hong, C \& Shin, D., 2004, Relationship between environmental tobacco smoke and urinary cotinine levels in passive smokers and their residences. Journal of Exposure Analysis and environmental Epidemiology, 14, 565 - 70.

Kim, S.R., Wipfli, H., Avila-Tang, E., Samet, M.J \&Breysse, N. P., 2008, Method for validation of hair nicotine level in non - smokers. Biomedical Chromatography, 23, $273-279$.

Kim, S., Wipfli, H., Navas - Acien, A., Dominiei, F., Avila-Tang, E., Onicescu, G., Breysse, P \&Samet, M. J., 2009, Determinants of hair nicotine concentrations in non - smoking women and children: A multicounty study on second hand smoke exposure in homes. Cancer, Epidemiology, Biomarkers \& prevention, 18, 3407 - 3413.

Kintz, P \&Mangin, P., 1993, Determination of gestational opiate, nicotine, benzodiazepine, cocaine and amphetamine exposure by hair analysis. Journal of Forensic Science, 33, $139-142$.

Kintz, P., Ludes, B \&Mangin, P., 1992, Evaluation of nicotine and cotinine in human hair. Journal of Forensic Science, $37,72-76$.

Knight, G. J., Wylie, P., Holman, M. S. \&Haddow, J. E., 1985, Improved ${ }^{125}$ I immunoassay for cotinine by selective chemistry. Clinical Chemistry, 31, $118-121$.

Knight, G.J., Palomaki, G.E., Lea, D.H \&Haddow, J.E., 1989, Exposure to environmental tobacco smoke measured by cotinine ${ }^{125}$ I radioimmunoassay. Clinical Biochemistry, 35, 1030 - 1039.

Kuhn, J., Vollmer,T., Martin,C.,Hendig, D \&Knabbe, C., 2012, Fast, simple cleanup free measurement of nicotine and cotinine by stable isotope dilution ultra-performance liquid chromatography-tandem mass spectrometry. Journal of Pharmaceutical and Biomedical Analysis, 67, 137 - 143.

Kuo, W.H., Yang, J.S \& Chiu C.M., 2001, Determination of urinary and salivary cotinine using gas and liquid chromatography and enzyme linked immunosorbent assay. Journal of Chromatography B, 768, 297- 303.

Langone, J. J \& Van Vunakis, J. J., 1987, Radioimmunoassay of nicotine, cotinine, and y (3-pyridyl)-yoxo-Nmethylbutyramide. Methods Enzymology, 84, 628 - 640.

Langone, J. J., Gjika, H. B \& Van Vunakis, H., 1973, Nicotine and its metabolites. Radioimmunoassays for nicotine and cotinine. Biochemistry 12, $5025-5030$.

Li, Z., Wang, B.,Ge, S., Yan, L., Liu, Y., Li, Z \& Ren, A., 2016, A simultaneous analysis method of polycyclic aromatic hydrocarbons, nicotine, cotinine and metals in human hair. Environmental Pollution, 219, 66 - 71.

Liang, H.R., Foltz, R. L., Meng, M \& Bennett, P., 2003, Ionization enhancement in atmospheric pressure chemical ionization and suppression in electrospray ionization between target drugs and stable isotope - labelled internal standard in quantification liquid chromatography tandem mass spectrometry. Rapid Communication in Mass Spectrometer, 17, $2851-2821$. 
Liu, W., Cassano, L.C., Xu, X \& Fan, H. Z., 2013, Laminated paper - based analytical devices (LPAD) with origami enable chemiluminiscenceimmuno assay for cotinine detection in mouse. Analytical Chemistry, 85, 1027 - 10276.

Mahoney, G.N \& Al-Delaimy., 2001, Measurement of nicotine in hair by reversed phase high performance liquid chromatography with electrochemical detection. Journal of Chromatography B, 753, 179 - 187.

Mallet, C.R., Lu, Z \&Mazzzeo, J.R., 2004, A study of ion suppression effects in electrospray ionization from mobile phase additives and solid phase extracts. Rapid Communication in Mass Spectrometry, 18, 49 - 58.

Man, C.N., Gam, L., Ismail, S., Lajis, R \&Awang, R., 2006, Simple, rapid and sensitive assay method for simultaneous quantification of urinary cotinine and nicotine using gas chromatography - mass spectrometry. Journal of Chromatography B, 844, $322-327$.

Matsukura, S., Sakamoto, N., Seino, Y.,Tamada,T., Matsuyama, H. \&Muranka, H., 1979, Cotinine excretion and daily cigarette smoking in habituated smokers. Clinical Pharmacology, 25, $555-561$.

Matsumoto, A., Ino, T., Ohta, M., Otani, T., Hanada, S., Sakuraoka, A., Matsumoto, A., Ichiba, M \& Hara, M., 2010, Enzyme-linked immunosorbent assay of nicotine metabolites. Environmental Health Preview, 15, 211 - 216.

Matuszewski, B. K., Constanzer, M.L \&Charez - Engem., 1998, Matrix effect in quantitative LC-MS-MS analyses of biological fluids: A method for determination of finasteride in human plasma at pictogram per milliliter concentration. Analytical Chemistry, 70, $882-889$.

Mc Ewen, C. N., Mc Kay, R.G \& Larsen B.S., 2005, Analysis of solids, liquids and biological tissue using solid probe introduction at atmospheric pressure on commercial LC/MS instruments. Analytical Chemistry, 77, 7826 - 31.

McManus, K.T., DeBethizy, J.D., Garteiz, D.A., Kyerematen, G.A \& Resell, E.S., 1990, A new quantitative thermospray LC-MS method for nicotine and its metabolite in biological fluids. Journal of Chromatographic Science, $28,510-16$.

Nakajima, M., Yamamoto, T., Kuroiwa, K \& Yokoi, T., 2000, Improved highly sensitive method for determination of nicotine and cotinine in human plasma by high performance liquid chromatography.

Journal of Chromatography B, 742, $211-215$.

Niblet, P., 2015, Statistics in smoking. Health and Social Care Information Center, 1, 2 - 76.

O'Malley, M., King, N. A., Conte, M., Ellingrod, L.V \&Ramnath, N., 2014, Effect of cigarette smoking on metabolism and effectiveness of systemic therapy for lung cancer. Journal of Thoracic Oncology, 9, 917 - 927.

Oddoze, C., Pauli, A.M \&Paster, J., 1998, Rapid and sensitive high performance liquid chromatographic determination of nicotine and cotinine in non-smoker human and rat urines. Journal of Chromatography B, 54, 95 101.

Parzynski, S.C., Jaszyna-Gasior, M., Franken, H.F \&Moolchan, T.E., 2008, Measuring nicotine intake among highlydependent adolescent smokers: comparability of saliva and plasma cotinine concentration, Pharmacology. Biochemistry and Behavior, 89, 145 - 149.

Pitt, J. J., 2009, Principles and applications of LC-MS in clinical biochemistry. The Clinical Biochemist Review, 30, $19-34$.

Pradel, S.J., Munshi, Z., Jackson, A., Murphy, M., Brown, M \& Tong, G.W., 2016, Ultra-sensitive laser wave mixing spectroscopic method for detection and separation of biomarkers and carcinogenic pollutants.

Instrumentation and Camera System, 9948, 1 - 8. 
Ramdzan, A.N., Barreiros, L, Almeida, G. S. I.M., Kolev, D.S \& Segundo, A.M., 2016, Detemination of salivary cotinine through solid phase extraction using a bead -injection lab-on-valve approach hyphenated to hydrophilic interaction liquid chromatography. Journal of Chromatography A, 1492, $284-291$.

Ramdzan, A.N., Barreiros, L., Almedia, I. G.S., Kelvin, S.D \& Segundo, A. N., 2016, Determination of salivary cotinine through solid phase extraction using a bead-injection lab-on-valve approach hyphenated to hydrophilic interaction liquid chromatography. Journal of Chromatography A, 1429, $284-291$.

Ramos, L., 2012, Critical overview of contemporary sample preparation techniques. Journal Chromatography A, $1221,84-98$.

Royal College Physicians., 2016, Nicotine without smoke. Tobacco Harm Reduction, 1, 1-206.

Rustemeier, K., Demetriou, D., Schepers, G \&Voneken, P., 1993, High performance liquid chromatographic determination of nicotine and its urinary metabolitesvia their 1,3-diethyl-2-thiobarbituric acid derivative. Journal of Chromatography B, 6, $294-296$.

Shin, H.S., Kim, J.G., Shin, Y.J \&Jee, S.H., 2002, Sensitive and simple method for the determination of nicotine and cotinine in human urine, plasma and saliva by gas-chromatography-mass spectrometry.

Journal of Chromatography A, 769, 177 - 183.

Smith, J.J., Robinson, F.R., Khan, A. R., Sonsnott, S.C. \& Dillard, A.D., 2014, Estimating cotinine associations and a saliva cotinine level to identify active cigarettes smoking in Alaska nat,ive pregnant women. Maternal and child Health Journal 18 (1), 120 - 128.

SRNT subcommittee on biochemical verification, 2002, Biochemical verification of tobacco use and cessation. Nicotine and Tobacco Research, 4, 149 - 159.

Stragierowicz, J., Mikolajewska, K., Zawadzka-Stolarz, M., Polanska, K \&Ligocka, D., 2013, Estimation of cutoff values of cotinine in urine and saliva for pregnant women in Poland. Hindawi, 2013, $1-12$.

Teeuwen, A. W.H., Alders, W.J.R. \& Van Rossum, M.J., 1989, Simultaneous estimation of nicotine and cotinine levels in biological fluids using high resolution capillary-column gas chromatography with solid phase extraction. Molecular Biology Reports 13 (3), 165 - 175.

Thomas, J. L., Guo, H., Carmella, G. S., Balbo, S., Han, S., Davis, A., Yoder, A., Murphy, E. S., An, C. L., Alhuwala, S. J \& Hecht, S.S., 2011, Metabolites of a tobacco-specific lung carcinogen in children exposed to secondhand or third hand tobacco smoke in their homes. Cancer Epidemiology, Biomarker and Prevention, 6, 1231 1221.

Torano, J.S \& Van Kan, H. J. M., 2003, Simultaneous determination of the tobacco smoke uptake parameters nicotine, cotinine and thiocyanate in urine, saliva and hair using gas chromatography-mass spectrometry for characteristic of smoking status of recently exposed subjects. Analyst, 128, $838-843$.

Torano, J.S \& Van Kan, H.J.M., 2003, Simultaneous determination of the tobacco smoke uptake parameters nicotine, cotinine and thiocyanate in urine, saliva and hair using gas chromatography-mass spectrometry for characterization of smoking status of recently exposed subjects. Analyst, 128, $838-843$.

Tricker, R. A., 2006, Biomarkers derived from nicotine and its metabolites: A review. International Contributors to Tobacco Smoke, 22, 1 - 29.

Tsuji, M., Mori, Y., Kanda, H., Ito, T., Hidaka, T., Kakamu, T., Kumagai, T., Hayakawa, T., Osaki, Y \& Fukushima, T., 2013, Development of simple HPLC/UV with a column switching method for the determination of nicotine and cotinine in hair samples. Health, 5, 687 - 694. 
Tuomi, T., Johnsson, T \&Reijuia, K., 1999, Analysis of nicotine, 3-hydroxycotinine, cotinine and caffeine in urine of passive smokers by HPLC-tandem mass spectrometry. Clinical Chemistry, 45, 2164 - 2172.

Umetsu, T., 1993, Therapeutic drug monitoring in hair sample. Clinical Pharmacokinetics, 25, 83 - 87.

Van, Maanen, J. M. S., Mass, L. M., Hageman, G., Klinjans, J. C. S \& Van Agen, B., 1994, DNA adducts and mutation analysis in white blood cells of smokers and non-smokers. Environmental Molecular Mutagen, 24, 49 - 50.

Watts, R. R., Langone, J. J., Knight, J. G. \&Lewtas, J., 1990, Cotinine analytical workshop report: consideration of analytical methods for determining cotinine in human body fluids as a measure of passive exposure to tobacco smoke. Environmental Health Perspectives, 84, 173 - 182.

Woodward, A., Fowls, J., Dickson, S., Fernando, D., Berezowski, R \& Reid, P., 2005, Increase in Saliva cotinine after 3 hours of exposure to second hand smoke in bars. Australian and New Zealand Journal of public Health, 29, $272-275$.

Xu, X \& Fan, H.Z., 2012, Concentration and determination of cotinine in serum by cation-selective exhaustive injection and sweeping Micellar - electrokinetic chromatography. Electrophoresis, 33, 2570 - 2576.

Yang, J., Hu, Y., Cai, B.J., Zhu, L.X., Su, D.Q., Hu, Q.Y \& Laing, F.X., 2007, Selective hair analysis of nicotine by molecular imprinted solid phase extraction: An application for evaluating tobacco smoke exposure. Science Direct, 45, $896-903$.

Yoshika, N., Dohi, Y \&Yonemasu, K., 1998, Development of simple and rapid ELISA of urinary cotinine for epidemiological applications. Environmental Health and Preventive Medicine, 3, 12 - 16.

Yuan, J. M., Butler, M. L., Stepanov, I \& Hecht, S. S., 2014, Urinary tobacco smoke constituent biomarkers for assessing risk of lung cancer. American Association for Cancer Research, 74, $401-411$.

Zuccaro, P., Pichini, S., Altieri, I., Rosa, M., Pellegrini, M \& Pacific, R., 1997, Interferences of nicotine metabolites in cotinine determination. Journal of Clinical Chemistry, 43, $180-181$. 